\title{
Exergy Assessment of Single Stage Solar Adsorption Refrigeration System Using ANN
}

\author{
V. Baiju and C. Muraleedharan \\ Department of Mechanical Engineering, National Institute of Technology Calicut, Kerala 673601, India \\ Correspondence should be addressed to V. Baiju, baij84@yahoo.co.in
}

Received 18 May 2012; Accepted 13 June 2012

Academic Editors: G. A. Britton and Y. He

Copyright ( $) 2012$ V. Baiju and C. Muraleedharan. This is an open access article distributed under the Creative Commons Attribution License, which permits unrestricted use, distribution, and reproduction in any medium, provided the original work is properly cited.

\begin{abstract}
A new approach based on artificial intelligence is proposed here for the exergy assessment of solar adsorption refrigeration system working with activated carbon-methanol pair. Artificial neural network model is used for the prediction of exergy destruction and exergy efficiency of each component of the system. Pressure, temperature and solar insolation are used as input variables for developing the artificial neural network model. The back propagation algorithm with three different variants such as CGP, SCG and LM are used in the network A and network B. The most suitable algorithm and the number of neurons in hidden layer are found as LM with 9 for network A and SCG with 17 for the Network B. The artificial neural network predicted results are compared with the calculated values of exergy destruction and exergy efficiency. The $R^{2}$ values of the exergy destruction and exergy efficiency of components (condenser, expansion device, evaporator, adsorbent bed, solar concentrator and overall system) are found to be close to 1 . The RMS and COV values are found to be very low in all cases. The comparison of the results suggests that the artificial neural network provided results are within the acceptable range.
\end{abstract}

\section{Introduction}

The conventional refrigeration systems require mechanical energy as the driving source and are responsible for the emission of $\mathrm{CO}_{2}$ and the other greenhouse gases such as CFCs and HFCs which are considered major cause for ozone layer depletion. From this context the adsorption refrigeration system attains a considerable attention in 1970s due to the energy crisis and ecological problems related to the use of CFCs and HFCs. Research has proved that the adsorption refrigeration technology has a promising potential for competing with the conventional vapour compression refrigeration systems. In comparison with the vapour compression refrigeration systems, adsorption refrigeration systems have the benefits of energy savings if powered by waste heat or solar energy, like simpler control, absence of vibration, and low-operation cost.

The major attraction of solar adsorption refrigeration is that its working fluids satisfy the Montreal protocol on ozone layer depletion and the Kyoto protocol on global warming [1]. The consumption of low-grade energy by the adsorption units does not possess any problems of emission of greenhouse gases. Furthermore, solar-power-based refrigerator is simple and is adaptable for small, medium, or large systems [2]. Use of ozone-friendly refrigerants and ability to utilize the renewable energy sources the adsorption systems can be preferred as an alternative to the conventional refrigeration systems $[3,4]$. The low COP and SCP values as compared to the conventional refrigeration systems are the barriers for the commercialization of the adsorption refrigeration systems $[5,6]$. For the improvement of the system a detailed computational and thermodynamic analysis must be carried out. These cycles are generally evaluated in terms of cycle coefficient of performance (COP). The first law based analysis does not consider the quality of input energy.

Nowadays a more generic approach based on the second law is used for the analysis of thermal energy systems. The conventional energy analysis does not give the qualitative assessment of the various losses occurring in the system components [7]. The second law analysis is used to get a clear picture of various losses quantitatively as well as qualitatively [8]. Exergy analysis provides a clear distinction between the 
energy losses to the environment and internal irreversibility in the process. Exergy analysis is a methodology for the evaluation of performance of devices and processes, and involves examining the exergy at different points in a series of processes. With this information, efficiencies can be evaluated and process steps having the largest losses can be identified.

The thermodynamic analyses of adsorption systems are complex because of the complex differential equations involved. Instead of solving complex differential equations and applying the limited number of experimental data, faster and simpler solutions can be obtained by using artificial neural network. ANNs are able to learn the key information patterns within multidimensional information domain. The use of ANN for the performance prediction and simulation of complex system has increasingly become popular in the last few years.

The application of artificial neural network for the exergy performance prediction of solar adsorption refrigeration system working at different conditions is necessary nowadays for making the analysis simple. Many earlier studies have reported the application of artificial neural network for the performance predictions of vapour compression refrigeration systems such as for direct expansion heat pump [9], for modeling solar cooling systems [10], and for modeling cascade refrigeration systems [11] with the acceptable accuracy. In the present work the artificial neural model is developed to assess the exergy performance of solar adsorption refrigeration system for different working conditions.

Recently some works about the use of ANN in energy systems have been published [12-20]. From the brief literature review cited, it can be observed that the many investigators have used the artificial neural network for the performance prediction of various thermal energy systems. No work has reported the applicability of artificial neural network for the exergy assessment of the solar adsorption refrigeration system. Hence, in the present work, ANN is developed to assess the exergy performance of a solar adsorption refrigeration system for different working conditions.

\section{Solar Adsorption Refrigeration System (SAR)}

2.1. System Description. The solar-assisted adsorption refrigeration system consists of a parabolic solar concentrator, water tank, adsorbent bed, condenser, expansion device (capillary tube), and an evaporator as shown in Figure 1 and its photograph is shown in Figure 2. The specifications of the components used in the system are given in Table 1. The experimental set-up is located in the Solar Energy Laboratory at National Institute of Technology Calicut, Kerala, India. The solar adsorption refrigeration system is tested under the meteorological conditions of Calicut (latitude of $11.15^{\circ} \mathrm{N}$, longitude of $75.49^{\circ} \mathrm{E}$ ) during April 2011.

2.2. Experimentation. Water gets heated starting from morning while flowing through the solar concentrator by natural circulation. When the hot water is circulated around the adsorbent bed, the temperature in the adsorbent bed increases. This causes the vapour pressure of the adsorbed refrigerant to reach up to the condensing pressure. The

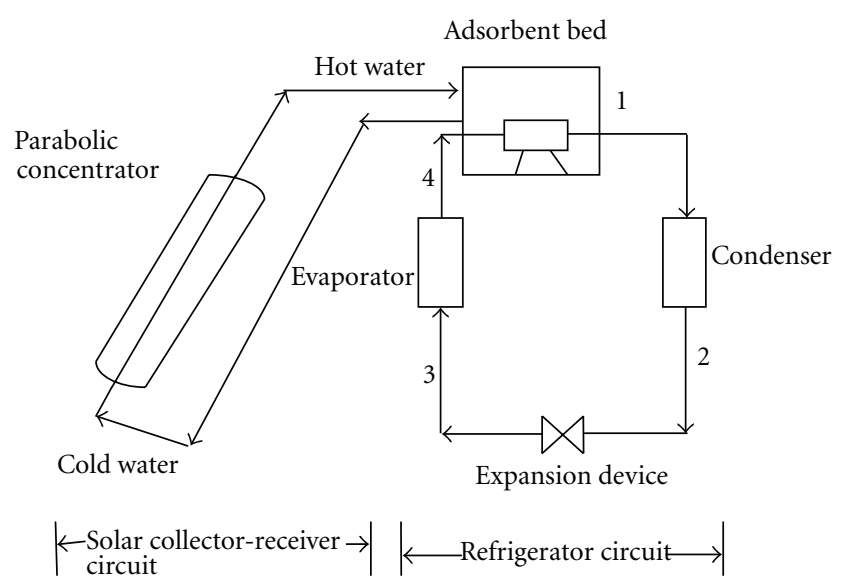

FIGURE 1: Schematic of solar adsorption refrigeration system.

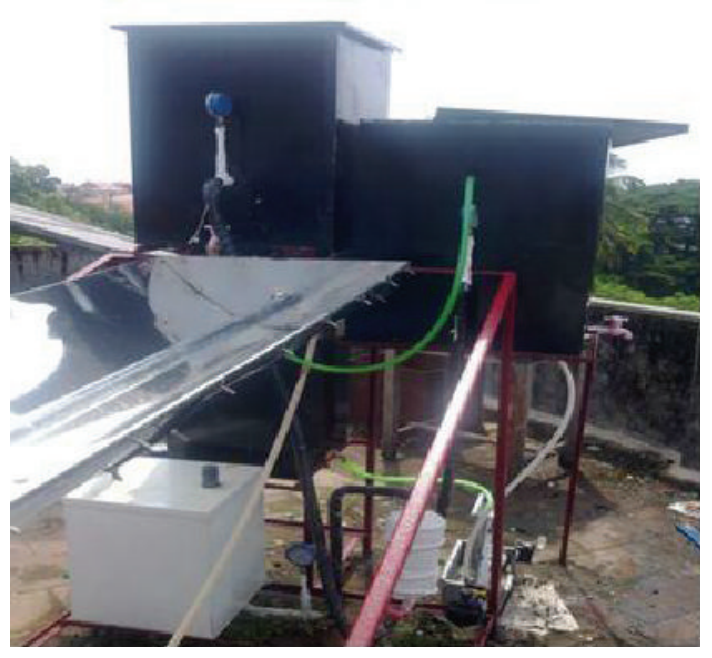

Figure 2: Photographic view of the system.

desorbed vapour is liquefied in the condenser. The highpressure liquid refrigerant is expanded through the expansion device to the evaporator pressure. The low-pressure liquid refrigerant then enters the evaporator where it evaporates by absorbing the latent heat of evaporation. In the evening, the hot water from the tank should be drained off and is refilled with cold water. The temperature of the adsorbent bed reduces rapidly and the pressure in the adsorber drops below the evaporator pressure.

The experiments are carried out keeping the evaporator temperature constant. The same procedure is repeated for the different evaporator loads.

2.3. Measurements. A digital pyranometer with an accuracy of $\pm 5 \mathrm{~W} / \mathrm{m}^{2}$ is placed near the solar collector to measure the instantaneous solar insolation. Pressure is measured during heating (desorption) of refrigerant, that is, condensing pressure and during cooling (adsorption), that is, evaporator pressure. The pressure gauges are fixed at the adsorbent bed in order to measure the pressure inside the adsorbent bed at 
TABLE 1: Specifications of the main components of solar adsorption refrigeration system.

\begin{tabular}{lc}
\hline Component & Technical specifications \\
\hline Condenser & Type: shell and coil \\
& Capacity: $200 \mathrm{~W}$ \\
Water cooled & Type: shell and coil \\
& Material: copper \\
Evaporator & Capacity: $150 \mathrm{~W}$ \\
& Capillary tube \\
Expansion device & Type: rectangular \\
Adsorbent bed & Material: stainless steel \\
Parabolic solar & Solar concentrator of area $3 \mathrm{~m}^{2}$ made of \\
concentrator & stainless steel \\
Adsorbent & Activated carbon \\
Adsorbate & Methanol \\
\hline
\end{tabular}

TABLE 2: Uncertainty in different parameters.

\begin{tabular}{lcc}
\hline \multirow{2}{*}{ Components } & \multicolumn{2}{c}{ Total uncertainty (\%) } \\
& Exergy destruction & Exergy efficiency \\
\hline Condenser & \pm 7.6 & \pm 5.87 \\
Expansion device & \pm 7.3 & \pm 8.2 \\
Evaporator & \pm 2.68 & \pm 2.42 \\
Adsorbent bed & \pm 3.57 & \pm 6.72 \\
Solar concentrator & \pm 4.67 & \pm 7.1 \\
\hline
\end{tabular}

each stages of adsorption and desorption processes. The temperature at various points in the solar adsorption refrigeration system is measured by calibrated T-type (Copper - Constantan) thermocouples. The various temperatures observed are (1) temperature of the adsorbent bed during various processes, (2) temperature of the refrigerant at inlet and outlet of the condenser, expansion device exit, and evaporator outlet, (3) temperature of water entering the water tanks, and (4) temperature of chilled water in the evaporator box.

\section{Uncertainty Analysis}

Uncertainties in the experiments can arise from the selection, condition, and calibration of the instruments, environment, observation, and test planning. A more precise method of estimating uncertainty has been presented by Holman [21]. The method is based on a careful specification of uncertainties in the various primary experimental measurements. These measurements are then used to calculate some desired results of the experiments. In the present study pressure, temperature, and solar insolation are measured by using the instruments. The method of calculating uncertainty of components in energy based system is given by Hosoz and Ertunc [12].
The total uncertainties of the various calculated parameters are shown in Table 2

The total uncertainty arising due to independent variables is given by

$$
w_{R}=\left[\left(\frac{\partial R}{\partial x_{1}} w_{1}\right)^{2}+\left(\frac{\partial R}{\partial x_{2}} w_{2}\right)^{2}+\cdots+\left(\frac{\partial R}{\partial x_{n}} w_{n}\right)^{2}\right]^{1 / 2} .
$$

The result $R$ is a given function in terms of independent variables. Let $W_{R}$ be the uncertainty in the result and let $w_{1}, w_{2}, \ldots, w_{n}$ be the uncertainties in the independent variables.

\section{Exergy Assessment}

The second law of thermodynamics facilitates the assessment of maximum amount of achievable work in a given system with different energy sources. Exergy is the available energy for conversion from an energy source with a reference environmental condition. Therefore exergy represents the thermodynamic quality of an energy carrier. Exergy is an expression used for accounting the loss of available energy due to the entropy generation in the irreversible system or process.

The general exergy balance equation can be written as.

$$
\varepsilon_{\text {in }}=\varepsilon_{\text {out }}+\varepsilon_{\text {loss }} .
$$

The total exergy is given by the equation,

$$
\varepsilon=\varepsilon_{\text {chem }}+\varepsilon_{\text {phy }}+\varepsilon_{\text {kin }}+\varepsilon_{\text {pot }} .
$$

The major part of the exergy is physical exergy. Neglecting chemical, kinetic, and potential exergy,

$$
\varepsilon=\varepsilon_{\text {phy }} .
$$

Physical exergy is contributed by the exergy due to heat, work and mass flow.

The exergy balance equation in rate form can be written as

$$
\sum\left(1-\frac{T_{0}}{T_{i}}\right) \dot{Q}_{i}-\dot{W}+\sum \dot{m}_{\mathrm{in}} e_{\mathrm{in}}-\sum \dot{m}_{\mathrm{out}} e_{\mathrm{out}}=\dot{\varepsilon}_{\mathrm{loss}},
$$

where flow exergy is given by

$$
e=\left(h-h_{0}\right)-T_{0}\left(s-s_{0}\right) .
$$

Second law efficiency

$$
\eta_{\mathrm{II}}=1-\frac{\dot{\varepsilon}_{\text {loss }}}{\dot{\mathcal{\varepsilon}}_{\text {in }}} .
$$

The exergy analysis of the solar adsorption refrigeration system (SAR) is carried out with the following assumptions.

(1) The gaseous refrigerant behaves as an ideal gas.

(2) Pressure is assumed to be uniform inside the adsorbent bed. 
TABLE 3: Exergy balance of the different components of solar adsorption refrigeration system.

\begin{tabular}{lccc}
\hline Component & Exergy received $\dot{\varepsilon}_{\text {in }}(\mathrm{kW})$ & Exergy delivered $\dot{\varepsilon}_{\text {out }}(\mathrm{kW})$ & Irreversibility $($ exergy loss $) \dot{\varepsilon}_{\text {loss }}(\mathrm{kW})$ \\
\hline Condenser & $\dot{m}_{r} e_{1}+\dot{m}_{c} e_{c 1}$ & $\dot{m}_{r} e_{2}+\dot{m}_{c} e_{c 2}$ & $\dot{\varepsilon}_{\text {loss cond }}=\dot{m}_{r}\left(e_{1}-e_{2}\right)-\dot{m}_{c}\left(e_{c 2}-e_{c 1}\right)$ \\
Expansion device & $\dot{m}_{r} e_{2}$ & $\dot{m}_{r} e_{3}$ & $\varepsilon_{\text {loss expdevice }}=\dot{m}_{r}\left(e_{2}-e_{3}\right)$ \\
Evaporator & $\dot{m}_{r} e_{3}+\dot{Q}_{\text {eva }}\left(1-\left(T_{0} / T_{\text {source }}\right)\right)$ & $\dot{m}_{r} e_{4}$ & $\dot{\varepsilon}_{\text {loss evap }}=\dot{m}_{r}\left(e_{3}-e_{4}\right)+\dot{Q}_{\text {eva }}\left(1-\left(T_{0} / T_{\text {source }}\right)\right)$ \\
Adsorbent bed & $\dot{m}_{r} e_{4}+\dot{Q}_{g}\left(1-\left(T_{0} / T_{g}\right)\right)$ & $\dot{m}_{r} e_{1}$ & $\dot{\varepsilon}_{\text {loss adsbed }}=\dot{m}_{r}\left(e_{4}-e_{1}\right)+\dot{Q}_{g}\left(1-\left(T_{0} / T_{g}\right)\right)$ \\
Solar collector & $\dot{Q}_{i}\left(1-\left(T_{0} / T_{s}\right)\right)$ & $\dot{m}_{f}\left[\left(h_{f o}-h_{0}\right)-T_{0}\left(s_{f o}-s_{0}\right)\right]$ & $\varepsilon_{\text {loss solar coll }}=\dot{Q}_{i}\left(1-\left(T_{0} / T_{s}\right)\right)$ \\
& & & $-\dot{m}_{f}\left[\left(h_{f o}-h_{0}\right)-T_{0}\left(s_{f o}-s_{0}\right)\right]$ \\
\hline
\end{tabular}

(3) The mass transfer inside the adsorbent bed occurs only in the vapour phase.

(4) Potential, kinetic, and chemical effects are neglected.

(5) Mass flow rate of the refrigerant is assumed as constant.

(6) The adsorbent bed consists of uniform size particles; hence the bed porosity is a constant.

(7) All the processes are at steady state.

(8) The process in the expansion device is assumed to be isenthalpic.

(9) Losses in the ducts and valves are neglected.

The specific exergy (ex in $\mathrm{kJ} / \mathrm{kg}$ ) of various components of solar adsorption refrigeration system is calculated by using (6) and the total exergy rate is calculated from the following equation,

$$
E_{x}=m e_{x}
$$

The exergy balance of the various components of solar adsorption refrigeration system are calculated by using (6) and (8) are as shown in Table 3.

4.1. Overall System. The exergy destruction of overall system is determined as

$$
\begin{aligned}
\varepsilon_{\text {loss system }}= & \dot{\varepsilon}_{\text {loss adsbed }}+\dot{\varepsilon}_{\text {loss cond }}+\varepsilon_{\text {loss expdevice }} \\
& +\varepsilon_{\text {loss evap }}+\varepsilon_{\text {loss solar coll }} .
\end{aligned}
$$

\section{Artificial Neural Network Development}

An artificial neural network tries to recognize an approximate pattern between the inputs and their desired outputs by imitating their brain functions. Their ability of learning by examples makes the ANN more flexible and powerful than the parametric approaches. An ANN compromises interconnected groups of artificial neurons and their respective weight-building blocks. The behavior of the network is largely dependend upon the interaction between these building blocks which are used in training the network in order to perform a particular function. Each neuron accepts a weighted set of inputs and responds with an output or activation function, which can be tangent sigmoid or log-sig function.

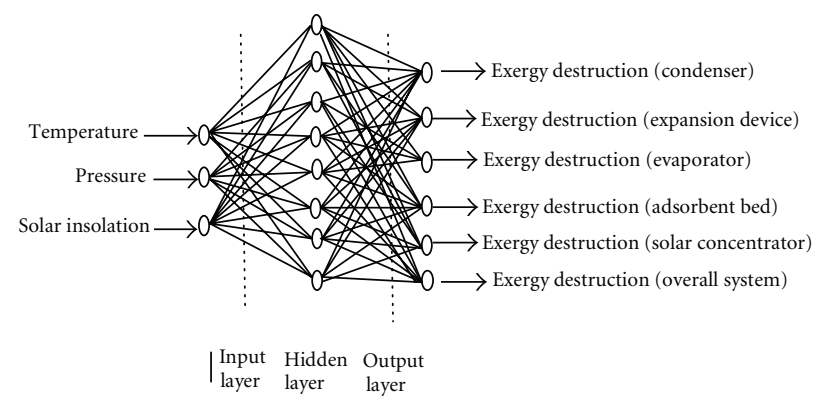

FIGURE 3: Network architecture for predicting exergy destruction (network A).

A typical ANN consists of the three layers, an input layer, a hidden layer made up of artificial neurons that transform the inputs, and an output layer that stores the results. ANNs are trained to get a specific target output from a particular input using a suitable learning method. Therefore the error between the desired output, and output of the network should be reduced by modifying the weights and biases.

In this study, a back propagation algorithm has been used in feed-forward, single hidden layer network. The ANN model was developed for SAR system with three neurons in the input layer (temperature, pressure, and solar insolation) and six neurons in the output layer (exergy destruction and exergy efficiency of condenser, expansion device, evaporator, adsorbent bed, solar concentrator, and overall system). The architecture of network selected in this work with names of input and output variables are shown in Figures 3 and 4.

The variants employed in the study are LM, SCG, and CGP. The inputs and outputs are normalized between 0 and 1. Logistic sigmoid (log-sig) transfer function is being used in ANN.

The transfer function used is given by

$$
f(Z)=\frac{1}{1+e^{-Z}}
$$

where $Z$ is the weighted sum of inputs.

The neural network tool box in the MATLAB (Version 7.8) is used for ANN modeling of SAR system. The back propagation algorithm optimizes the weight connection by allowing the error to spread from output layers towards the lower layers. The performance of ANN prediction is evaluated by regression analysis between the ANN outputs 


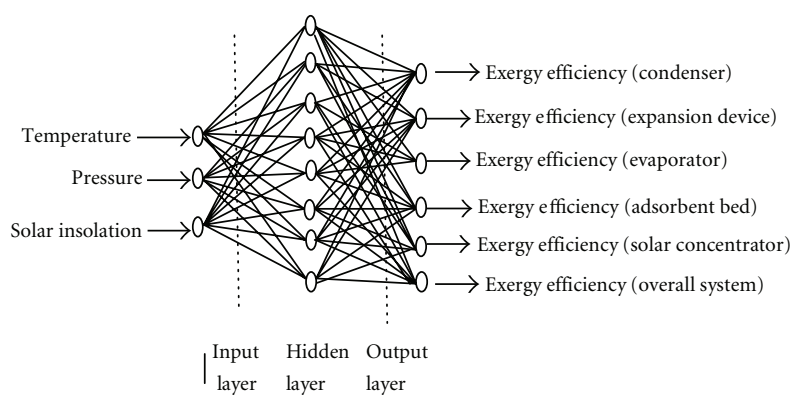

FIGURE 4: Network architecture for predicting exergy efficiency (network B).

TABLe 4: Statistical performance of the different algorithms evaluated for network A (exergy destruction).

\begin{tabular}{lcccc}
\hline Algorithm & Neurons in hidden layer & $R^{2}$ & RMS & COV \\
\hline LM & 8 & 0.99981 & 0.057 & 0.43 \\
LM & 9 & 0.99993 & 0.048 & 0.109 \\
LM & 10 & 0.99991 & 0.069 & 0.189 \\
SCG & 8 & 0.97941 & 0.098 & 0.476 \\
SCG & 9 & 0.98302 & 0.087 & 0.390 \\
SCG & 10 & 0.96276 & 0.19 & 0.204 \\
CGP & 8 & 0.9869 & 0.0205 & 0.198 \\
CGP & 9 & 0.96478 & 0.501 & 0.169 \\
CGP & 10 & 0.97916 & 0.023 & 0.183 \\
\hline
\end{tabular}

TABLE 5: Statistical performance of different algorithms evaluated for network B (exergy efficiency).

\begin{tabular}{lcccc}
\hline Algorithm & Neurons in hidden layer & $R^{2}$ & RMS & COV \\
\hline LM & 16 & 0.99847 & 0.0504 & 0.714 \\
LM & 17 & 0.9980 & 0.042 & 0.684 \\
LM & 18 & 0.99089 & 0.0596 & 0.78 \\
SCG & 16 & 0.99968 & 0.099 & 0.196 \\
SCG & 17 & 0.99980 & 0.051 & 0.176 \\
SCG & 18 & 0.99969 & 0.0695 & 0.24 \\
CGP & 16 & 0.9689 & 0.0805 & 0.95 \\
CGP & 17 & 0.9849 & 0.078 & 0.905 \\
CGP & 18 & 0.98914 & 0.058 & 0.802 \\
\hline
\end{tabular}

and experimental values. The criteria used for evaluating the network performance are, correlation coefficient $\left(R^{2}\right)$, root mean square error (RMS), and covariance (COV) which are defined as

$$
\begin{gathered}
\mathrm{RMS}=\left(\frac{1}{n} \sum_{j=1}^{n}\left[t_{j}-o_{j}\right]^{2}\right)^{1 / 2}, \\
R^{2}=1-\left(\frac{\sum_{j}\left[t_{j}-o_{j}\right]^{2}}{\sum_{j}\left(o_{j}\right)^{2}}\right), \\
\operatorname{COV}=\frac{\mathrm{RMS}}{\sum_{j} o_{j}} * 100 .
\end{gathered}
$$

TABLE 6: Statistical performance of the network A (exergy destruction).

\begin{tabular}{lcccc}
\hline \multirow{2}{*}{ Component } & \multicolumn{3}{c}{ Algorithm LM-9 } & Mean \% \\
& $R^{2}$ & RMS & COV & deviation \\
\hline Condenser & 0.9857 & 0.001269 & 0.2742 & 2.375 \\
Expansion device & 0.9843 & 0.003152 & 0.001075 & -2.58 \\
Evaporator & 0.9928 & 0.0008298 & 0.2309 & -1.41 \\
Adsorbent bed & 0.9971 & 0.001162 & 0.1614 & 0.96 \\
Solar concentrator & 0.9867 & 0.007812 & 0.0629 & 0.59 \\
Overall system & 0.9908 & 0.0178 & 0.0348 & -0.75 \\
\hline
\end{tabular}

The experimental data obtained from a series of experiments conducted in SAR at different evaporator loads have been used to train and test the network. The available data sets obtained from experimental observations are divided into training and testing sets. The data set consists of 90 input and output pairs. From these 80 sets are used for training the network and 10 for testing the network.

In the training, an increased number of neurons from 5 to 10 and from 12 to 18 are used for the networks A and B, respectively. During each step, the performance of network is checked with statistical performance parameters. The statistical performance of networks with different configurations (changing the number of neurons and training function) is shown in Tables 4 and 5. From the results it is clear that the LM algorithm with 9 number of neurons and SCG with 17 neurons are having maximum $R^{2}$, minimum RMS and COV values. So for network A, LM with 9 neurons, and for network B, SCG with 17 number of neurons in hidden layer are found to be optimum.

\section{Results and Discussion}

6.1. Performance of the Network Selected. During the training it is found that not all ANN configurations would produce the converged results. Among the converged results the configuration LM-9 and SCG-17 are found to be the most optimal for network $\mathrm{A}$ and network $\mathrm{B}$, respectively. The drops in mean square (MSE) with the number of epochs during training, testing, and validation process are shown in Figures 5 and 6 . From the figures it can be seen that the curves are very close. In these processes the autostop functions are imposed and the satisfactory results are obtained at 28 epochs for the network $A$ and at 50 for network $B$. The statistical performance values of the network A (LM9) and network B (SCG-17) used for predicting the exergy destruction and exergy efficiency are shown in Tables 6 and 7.

These results confirmed that the ANN predicted values are close to the experimental results with a maximum correlation coefficient for all the predictions (exergy destructions and exergy efficiency of condenser, expansion device, evaporator, adsorbent bed, solar concentrator, and overall system). The other statistical parameters such as RMS and $\mathrm{COV}$ values are found to be low. 
TABLE 7: Statistical performance of the network B (exergy efficiency).

\begin{tabular}{lcccc}
\hline \multirow{2}{*}{ Component } & \multicolumn{3}{c}{ Algorithm SCG-17 } & Mean \% \\
& $R^{2}$ & RMS & COV & deviation \\
\hline Condenser & 0.9973 & 0.0073 & 0.020 & 0.975 \\
Expansion device & 0.9846 & 0.00546 & 0.105 & -0.78 \\
Evaporator & 0.9981 & 0.00534 & 0.14 & -1.51 \\
Adsorbent bed & 0.9996 & 0.000526 & 0.549 & -0.45 \\
Solar concentrator & 0.9945 & 0.002743 & 0.357 & 2.78 \\
Overall system & 0.9803 & 0.002869 & 0.44 & -1.079 \\
\hline
\end{tabular}

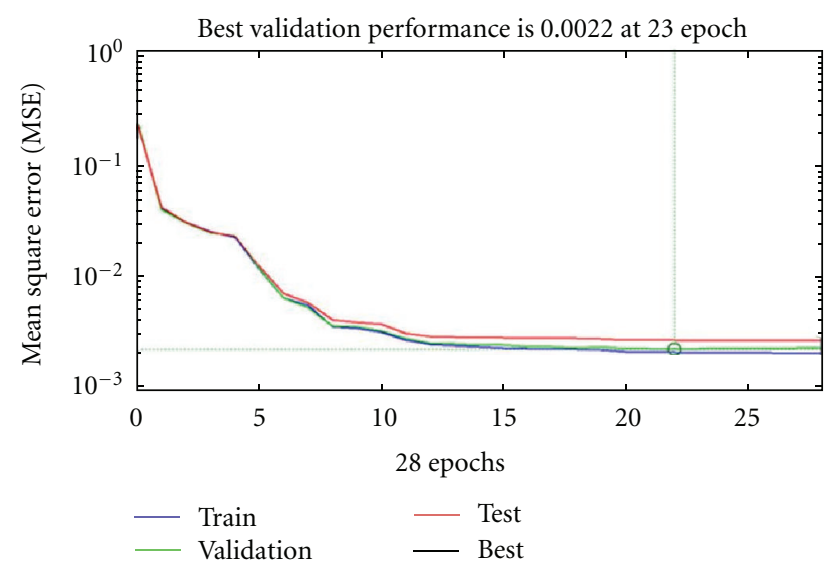

Figure 5: Mean square error plot for the LM-9 configuration.

\subsection{Exergy Assessment of Various Components of the SAR}

6.2.1. Condenser. The ANN predicted and experimental values of exergy destruction and exergy efficiency of condenser with heat source temperature are shown in Figures 7 and 8. The exergy destruction of condenser is found to be increased from 0.0357 to $0.06 \mathrm{~kW}$ with an average value of $0.0482 \mathrm{~kW}$ with increase in the heat source temperature, whereas exergy efficiency is found to be decreasing from $64 \%$ to $42 \%$. The exergy destruction and exergy efficiency of the condenser depend upon several parameters such as the inlet and outlet cooling water temperature, condensation temperature, and the internal irreversibility's during the condensation of vapour refrigerant. The source of internal irreversibility is de-superheating of the refrigerant vapour from desorption temperature to the condensation temperature. As the heat source temperature increases it increases the amount of refrigerant being desorbed from the adsorbent bed. The condensation of more amount of refrigerant releases more heat and needs a lower inlet cooling water temperature. Hence the higher amount of total heat transfer as well as increased temperature difference between the cooling water and the refrigerant vapour leads to augmentation of the irreversibility. Hence for a fixed heat transfer area and known condensation temperature the optimization of cooling water temperature is necessary to minimize the exergy destruction and to increase the exergy efficiency.

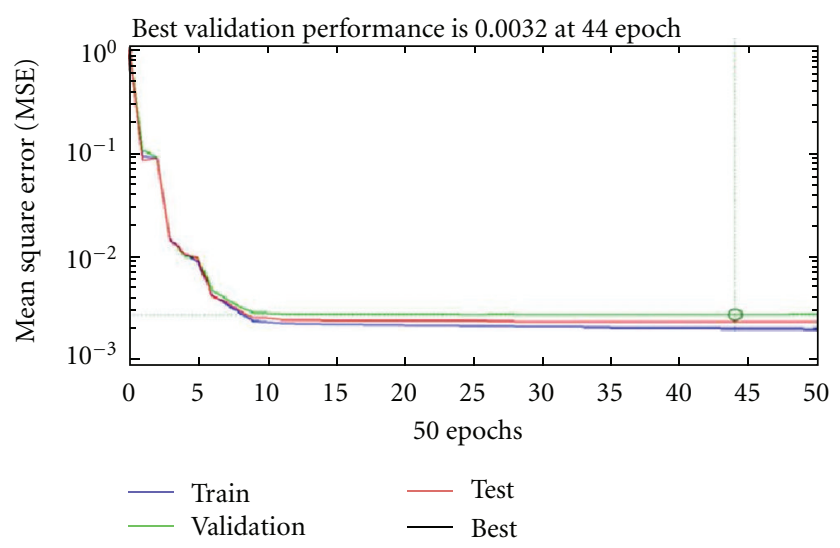

FIGURE 6: Mean square error plot for SCG-17 configuration.

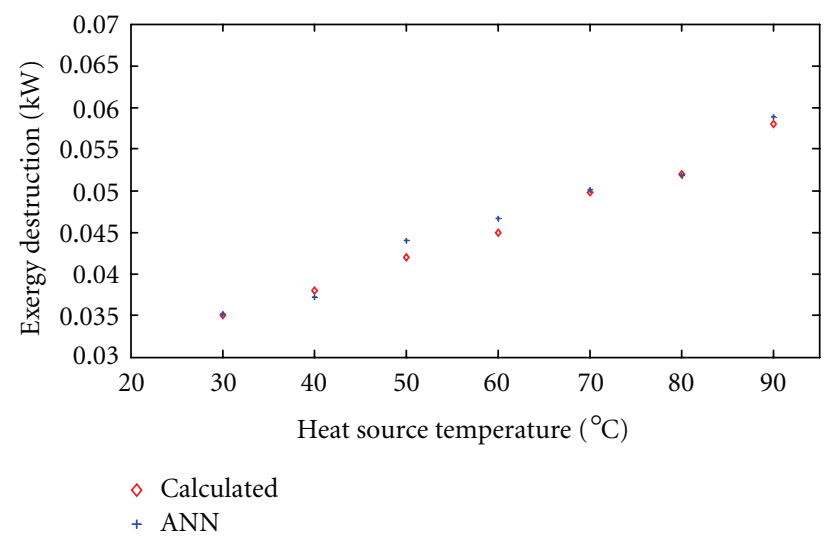

FIGURE 7: Variation of exergy destruction with heat source temperature (condenser).

The ANN predictions yield a correlation coefficient of 0.9857, RMS and COV values of 0.001269 and 0.2742 , respectively, for exergy destruction, and $0.9973,0.0073$, and 0.20 , respectively, for exergy efficiency. The comparison shows that the ANN predicted values are closer to calculated results.

6.2.2. Expansion Device. The variation of the ANN predicted and experimental values of exergy destruction and exergy efficiency of expansion device with the heat source temperature is shown in Figures 9 and 10. The variation of both exergy destruction and exergy efficiency with heat source temperature is found to be low. The exergy destruction in the expansion device is mainly due to the pressure drop of the refrigerants passing through it. The average values of exergy destruction and exergy efficiency are found as $0.0128 \mathrm{~kW}$ and $79.89 \%$, respectively. For reducing the exergy destruction the operating pressure of the system needs to be optimised. The ANN predictions yield a correlation coefficient of 0.9843 , RMS and COV values of $0.003152,0.001075$, respectively, for exergy destruction and 0.9846, 0.00546, and 0.105, respectively, for exergy efficiency. The comparison shows that the ANN predicted values are closer to experimental results. 


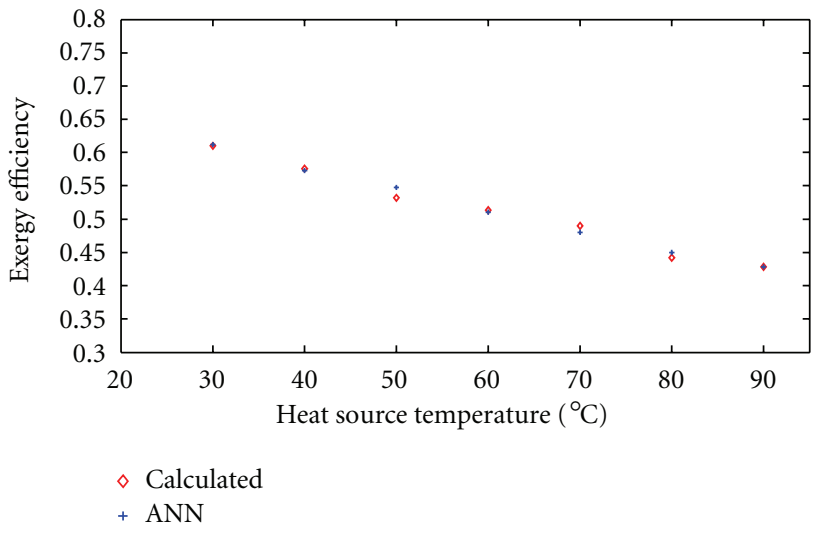

FIGURE 8: Variation of exergy efficiency of with heat source temperature (condenser).

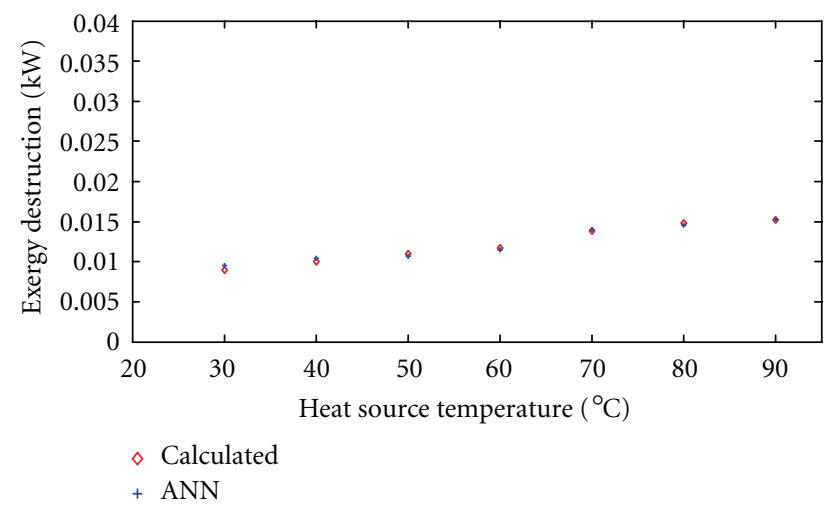

FIGURE 9: Variation of exergy destruction with heat source temperature (expansion device).

6.2.3. Evaporator. The ANN predicted and experimental values of exergy destruction and exergy efficiency of evaporator are depicted in Figures 11 and 12. From the figures it is clear that at very high heat source temperature exergy destruction is found to be very large and hence the lower exergy efficiency. The exergy destruction is mainly due to the irreversible phase change process of the refrigerant in the evaporator. The viscous pressure drops in the copper coils cause the pressure variations throughout the component. These pressure variations would lead to destruction in exergy in the evaporator segment of solar adsorption refrigeration system. The results reveal that the evaporator of SAR system needs further modifications.

The ANN predictions yield correlation coefficients of 0.9928 and 0.9981 for exergy destruction and exergy efficiency, respectively. The RMS and COV values for each case are found to be $0.0008298,0.2309$ and $0.00534,0.14$, respectively.

6.2.4. Adsorbent Bed. The ANN predicted and experimental values of exergy destruction and exergy efficiency of adsorbent bed with heat source temperature are shown in Figures 13 and 14. The exergy destruction increases from

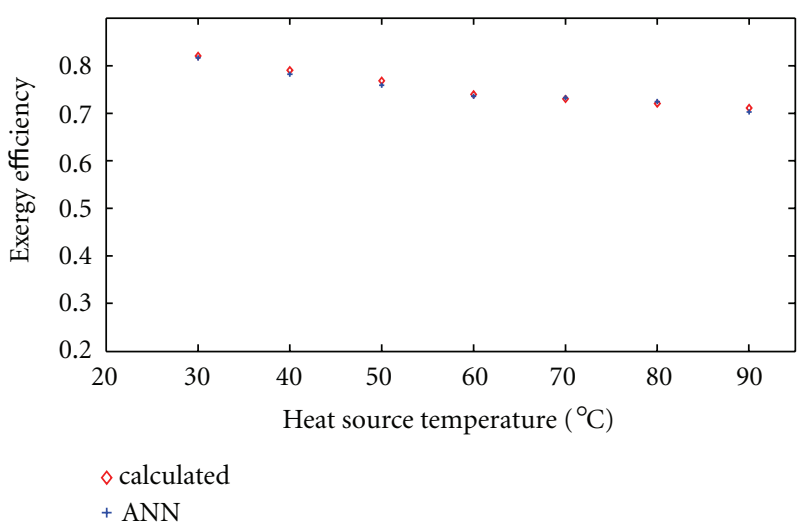

FIGURE 10: Variation of exergy efficiency of with heat source temperature (expansion device).

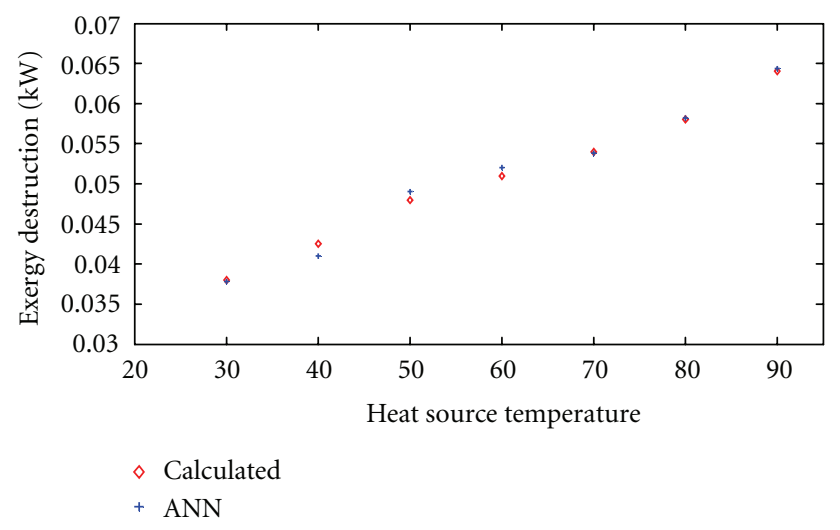

Figure 11: Variation of exergy destruction with heat source temperature (evaporator).

$0.082 \mathrm{~kW}$ to $0.14 \mathrm{~kW}$ with increase in heat source temperature due to high irreversibility associated with adsorption and desorption processes taking place in the adsorbent bed. The adsorbent bed is surrounded by the solar heated water in the water tank, as the heat source temperature (Solar heated water) increases the entropy generation also increases that leads to an increase in the irreversibility. The high irreversibility leads to a decrease in exergy efficiency. The results indicate that the operational parameters and material properties of the adsorbent bed should be optimized to reduce the exergy destruction and to improve the exergy efficiency. From the figures it is clear that the ANN predictions are in well agreement with the experimental results of both exergy destruction and exergy efficiency of the adsorbent bed. The correlation coefficient for both the cases are 0.9971 and 0.9996 , respectively. The RMS and COV values are $0.001162,0.1614$ and $0.000526,0.549$, respectively.

6.2.5. Solar Collector. The comparison of ANN predicted and experimental results of exergy destruction and exergy efficiency of solar collector with heat source temperature are depicted in Figures 15 and 16. The heat source temperature increases due to the increase in solar insolation. As the solar insolation increases more amount of heat is 


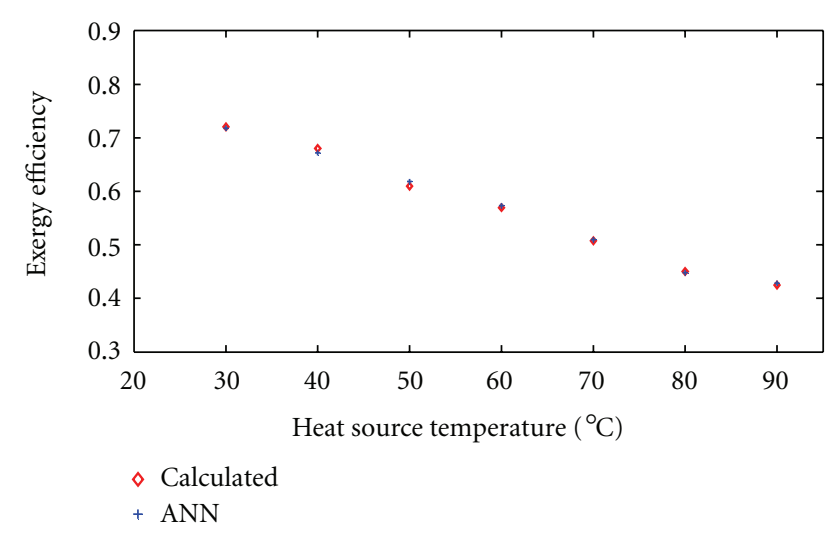

FIGURE 12: Variation of exergy efficiency with heat source temperature (evaporator).

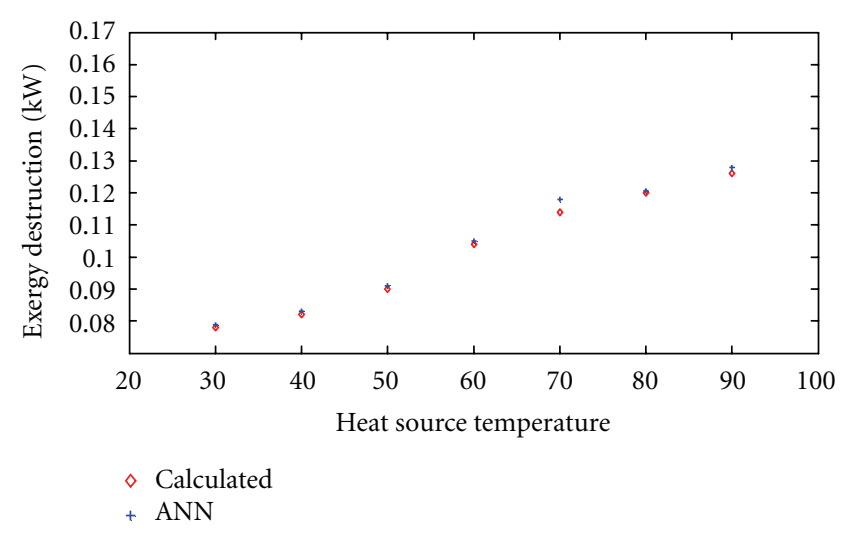

FIgURE 13: Variation of exergy destruction with heat source temperature (adsorbent bed).

absorbed through the concentrator. Hence exergy destruction decreases with increase in solar intensity and hence with the heat source temperature. The exergy destruction decreases from $1.98 \mathrm{~kW}$ to $1.89 \mathrm{~kW}$ with increase in heat source temperature. The results indicate that proper modifications and better design are required for the solar collector to reduce the exergy destruction to lower level.

The comparison between the ANN predictions and estimated values of exergy destruction and exergy efficiency yields a correlation coefficients of 0.9867 and 0.9945 , respectively. The RMS and COV values are 0.007812, 0.0629 and $0.002743,0.357$, respectively.

6.2.6. Overall System. The comparison between the ANN predicted and experimental results of system exergy destruction and exergy efficiency of SAR are depicted in Figures 17 and 18. The system exergy destructions and exergy efficiency varying the range of $2.42 \mathrm{~kW}$ to $2.82 \mathrm{~kW}$ and $8.2 \%$ to $14.6 \%$ with an average value of $2.68 \mathrm{~kW}$ and $10.87 \%$, respectively. System exergy destruction is found to increase with the increase in heat source temperature. The exergy destruction in the adsorbent bed and solar concentrator is significant in the overall system performance. This should be reduced by a better design and the optimum operation of the components.

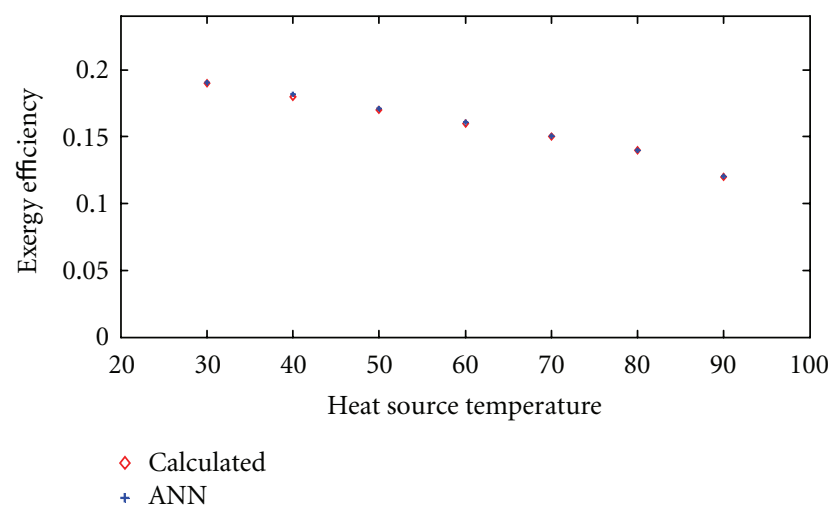

FIGURE 14: Variation of exergy efficiency with heat source temperature (adsorbent bed).

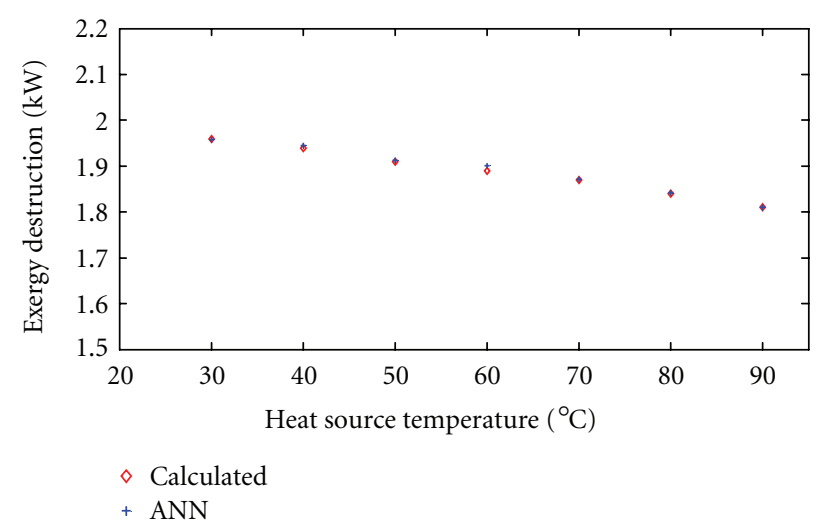

FIGURE 15: Variation of exergy destruction with heat source temperature (solar concentrator).

The exergy efficiency of the system is found to be first increasing, reaches a maximum, and then decreases. The exergy efficiency is found to be maximum in the range between $70^{\circ} \mathrm{C}$ and $75^{\circ} \mathrm{C}$. So for the system, the optimum operating point is to be defined. Baiju and Muraleedharan [22] conducted a study on effect of heat source temperature on cycle COP and exergy efficiency of the system. The study reveals that exergy efficiency decreases and cycle COP increases with the increase in heat source temperature. The optimum heat source temperature is found out by considering the point of intersection of increasing COP curves and decreasing exergetic curves. Thus for this particular system the optimum heat source temperature is found out as $72.4^{\circ} \mathrm{C}$, where the cycle COP and exergy efficiency reach maximum.

The comparison between the ANN predictions and experimental values of exergy destruction and exergy efficiency yields correlation coefficients of 0.9908 and 0.9803 , respectively. The RMS and COV values are $0.0178,0.0348$ and $0.002869,0.44$, respectively.

\section{Conclusions}

The exergy assessment of solar adsorption refrigeration system by using artificial neural network is carried out. The 


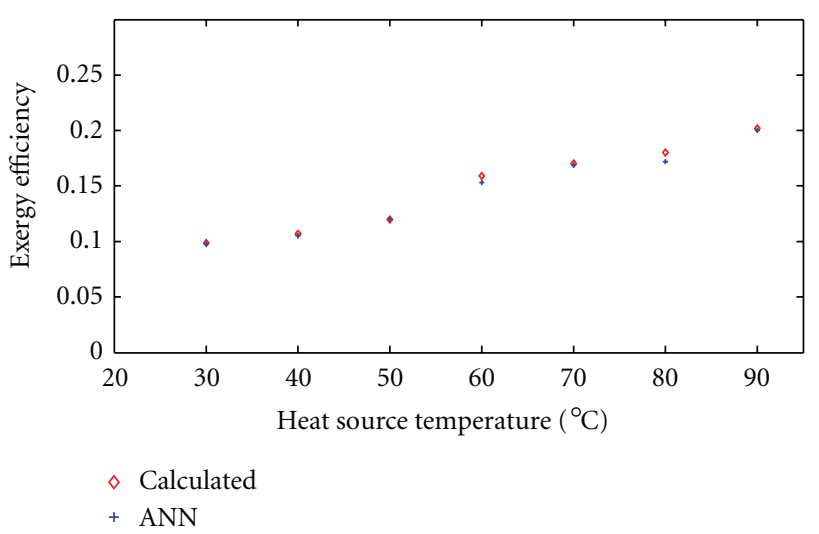

FIGURE 16: Variation of exergy efficiency with heat source temperature (solar concentrator).

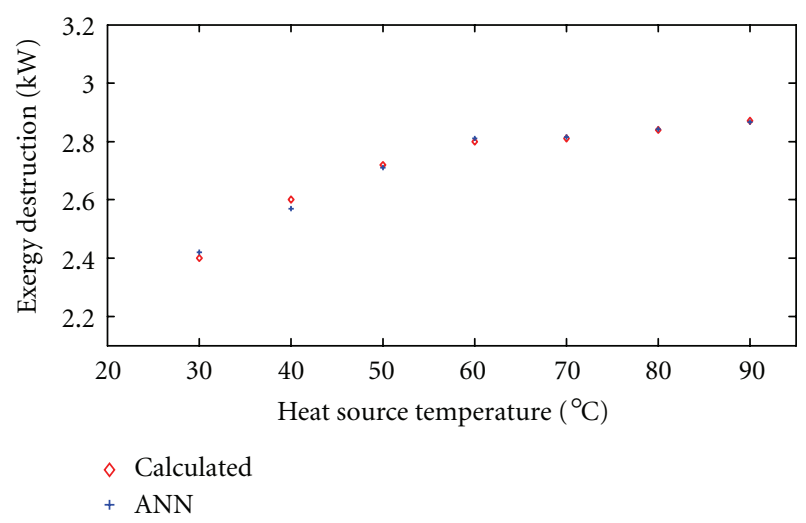

Figure 17: Variation of exergy destruction with heat source temperature (overall system).

energy and exergy balance equations have been derived using the first and second law of thermodynamics. The exergy loss and exergetic efficiency of each component of the system have also been estimated. In order to gather the data for training and testing the proposed ANN, an experimental system has been set up and tested for its performance at different evaporator loads.

The following conclusions are made from the present work.

(1) The exergy destruction and exergy efficiency of each component of solar adsorption refrigeration system has been calculated. The exergy destruction associated with the adsorbent bed is found to be on higher side and it increases with increase in heat source temperature.

(2) The operational parameters and material properties of the adsorbent bed should be optimized to reduce the exergy destruction and hence to improve the exergy efficiency.

(3) System exergy destruction is found to be increasing with the increase in heat source temperature, whereas the exergy efficiency of the system is found to first increase, reach a maximum, and then decrease. The

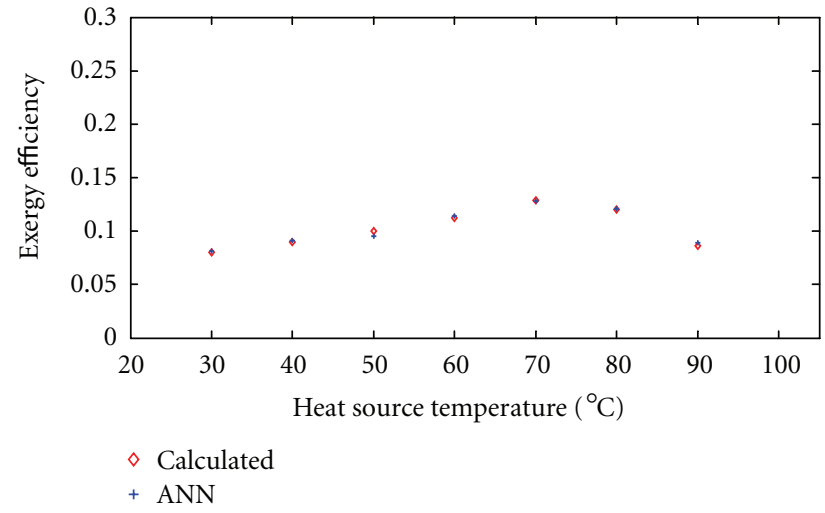

FIGURE 18: Variation of exergy efficiency with heat source temperature (overall system).

optimum operating point of the system is at heat source temperature of $72.4^{\circ} \mathrm{C}$.

(4) Using the three different parameters, namely, temperature, pressure, and solar insolation, an ANN model based on the back propagation algorithm is proposed for predicting the exergy destruction and exergy efficiency of each component of the solar adsorption refrigeration system.

(5) The performance of ANN predictions is measured using the three criteria root mean square error, correlation coefficient, and coefficient of variance. The network model demonstrated good results with correlation coefficients in the range of 0.9843 to 0.9971 and 0.9803 to 0.9996 for exergy destruction and exergy efficiency, respectively. The mean percentage of error from $0.59 \%$ to $2.375 \%$ and $0.45 \%$ to $2.78 \%$ for network $\mathrm{A}$ and network $\mathrm{B}$, respectively.

(6) The mean percentage of error in all cases is found to be within $\pm 5 \%$. The comparison of results suggests that the artificial neural network provided results are within the acceptable range.

(7) This study reveals that the ANN modelling can be effectively employed for the exergy assessment of solar adsorption refrigeration system with high degree of accuracy.

\section{References}

[1] E. E. Anyanwu, "Environmental pollution: restructuring the refrigeration industry as a way out," Environment Protection Engineering, vol. 26, no. 4, pp. 17-27, 2000.

[2] E. E. Anyanwu, "Review of solid adsorption solar refrigerator I: an overview of the refrigeration cycle," Energy Conversion and Management, vol. 44, no. 2, pp. 301-312, 2003.

[3] D. S. Jung and R. Radermacher, "Performance simulation of single-evaporator domestic refrigerators charged with pure and mixed refrigerants," International Journal of Refrigeration, vol. 14, no. 4, pp. 223-232, 1991.

[4] Y. S. Chang, M. S. Kim, and S. T. Ro, "Performance and heat transfer characteristics of hydrocarbon refrigerants in a heat 
pump system," International Journal of Refrigeration, vol. 23, no. 3, pp. 232-242, 2000.

[5] K. Sumathy, K. H. Yeung, and L. Yong, "Technology development in the solar adsorption refrigeration systems," Progress in Energy and Combustion Science, vol. 29, no. 4, pp. 301-327, 2003.

[6] N. M. Khattab, "A novel solar-powered adsorption refrigeration module," Applied Thermal Engineering, vol. 24, no. 17-18, pp. 2747-2760, 2004.

[7] D. E. Chelghoum and A. Bejan, "Second law analysis of solar collector with energy storage capacity," ASME Journal of Solar Energy Engineering, vol. 107, no. 3, pp. 244-251, 1985.

[8] A. F. Haught, "Physical consideration of solar energy conversion," ASME Journal of Solar Energy Engineering, vol. 106, no. 1, pp. 3-15, 1984.

[9] M. Mohanraj, S. Jayaraj, and C. Muraleedharan, "Modeling of a direct expansion solar assisted heat pump using artificial neural networks," International Journal of Green Energy, vol. 5, no. 6, pp. 520-532, 2008.

[10] M. Mohanraj, S. Jayaraj, and C. Muraleedharan, "Exergy analysis of direct expansion solar-assisted heat pumps using artificial neural networks," International Journal of Energy Research, vol. 33, no. 11, pp. 1005-1020, 2009.

[11] Y. H. Kuang, K. Sumathy, and R. Z. Wang, "Study on a directexpansion solar-assisted heat pump water heating system," International Journal of Energy Research, vol. 27, no. 5, pp. 531548, 2003.

[12] M. Hosoz and H. M. Ertunc, "Modelling of a cascade refrigeration system using artificial neural network," International Journal of Energy Research, vol. 30, no. 14, pp. 1200-1215, 2006.

[13] S. A. Kalogirou and M. Bojic, "Artificial neural networks for the prediction of the energy consumption of a passive solar building," Energy, vol. 25, no. 5, pp. 479-491, 2000.

[14] A. Pacheco-Vega, M. Sen, K. T. Yang, and R. L. McClain, "Neural network analysis of fin-tube refrigerating heat exchanger with limited experimental data," International Journal of Heat and Mass Transfer, vol. 44, no. 4, pp. 763-770, 2001.

[15] A. Palau, E. Velo, and L. Puigjaner, "Use of neural networks and expert systems to control a gas/solid sorption chilling machine," International Journal of Refrigeration, vol. 22, no. 1, pp. 59-66, 1999.

[16] A. Chouai, S. Laugier, and D. Richon, "Modeling of thermodynamic properties using neural networks: application to refrigerants," Fluid Phase Equilibria, vol. 199, no. 1-2, pp. 53-62, 2002.

[17] H. Bechtler, M. W. Browne, P. K. Bansal, and V. Kecman, "New approach to dynamic modelling of vapour-compression liquid chillers: artificial neural networks," Applied Thermal Engineering, vol. 21, no. 9, pp. 941-953, 2001.

[18] V. Baiju and C. Muraleedharan, "Prediction of performance parameters of single stage solar adsorption refrigeration system by ANN," ISRN Journal of Thermodynamics, vol. 2012, Article ID 102376, 8 pages, 2012.

[19] S. A. Kalogirou, S. Panteliou, and A. Dentsoras, "Artificial neural networks used for the performance prediction of a thermosiphon solar water heater," Renewable Energy, vol. 18, no. 1, pp. 87-99, 1999.

[20] T. T. Chow, G. Q. Zhang, Z. Lin, and C. L. Song, "Global optimization of absorption chiller system by genetic algorithm and neural network," Energy and Buildings, vol. 34, no. 1, pp. 103109, 2002.

[21] J. P. Holman, Experimental Methods For Engineers, McGrawHill, New Delhi, India, 7th edition, 2001.
[22] V. Baiju and C. Muraleedharan, "Performance study of a two stage solar adsorption refrigeration system," International Journal of Engineering Science and Technology, vol. 3, pp. 57545764, 2011. 

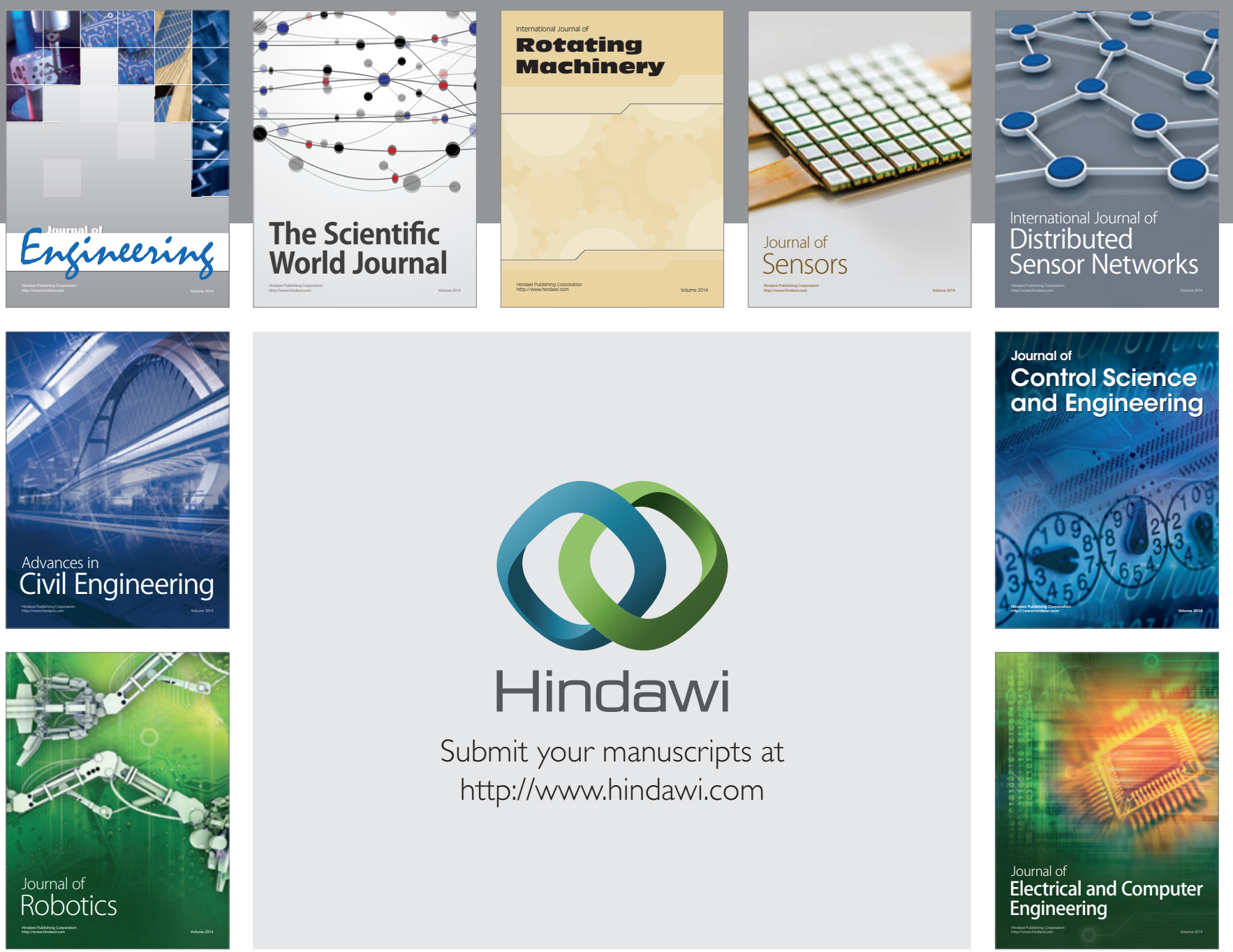

Submit your manuscripts at

http://www.hindawi.com
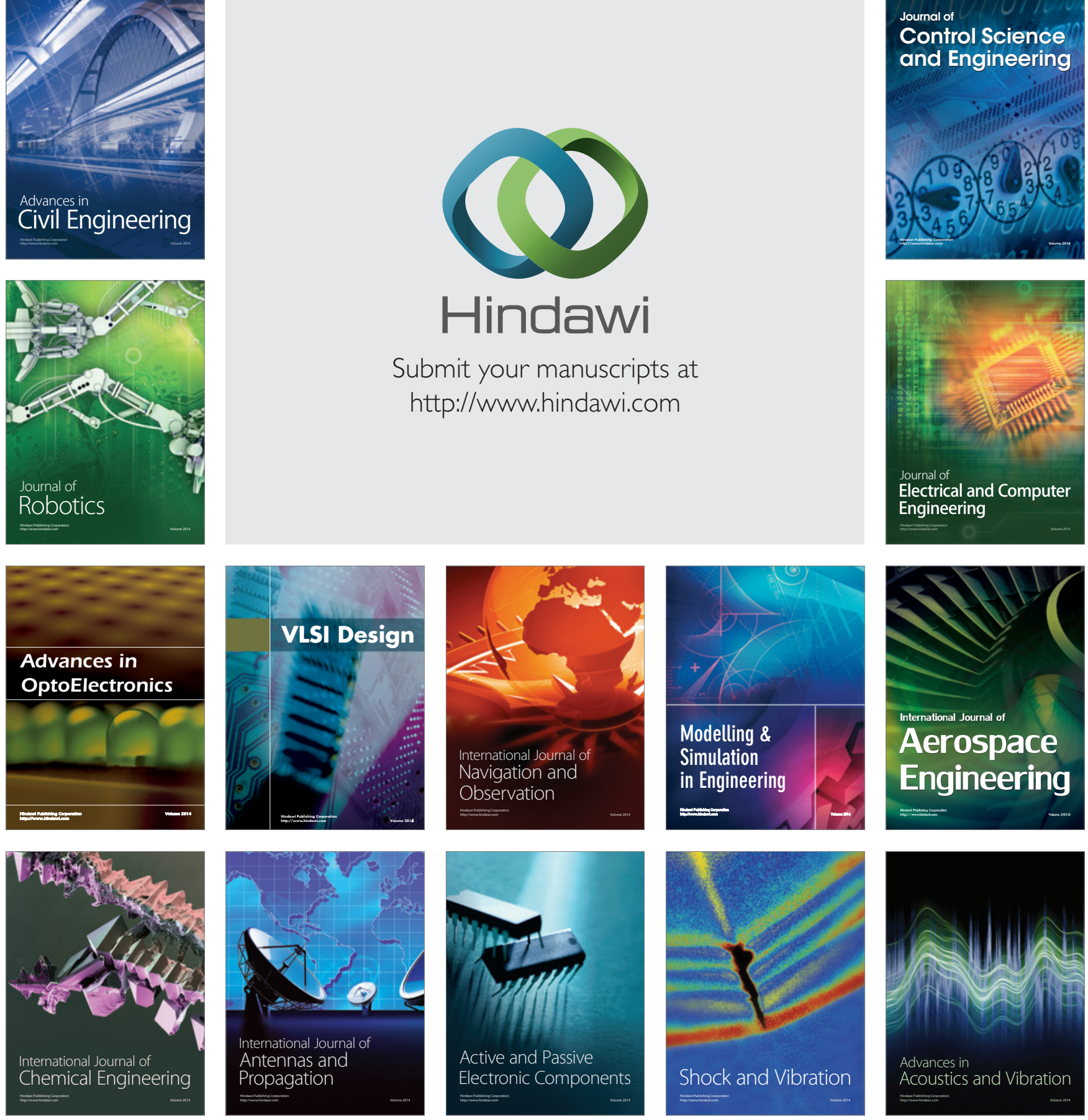